\title{
Mixtures of Vegetable Fat as a Potential Raw Material for Bakery
}

\section{IJCRR}

Section: Healthcare Sci. Journal Impact Factor: 6.1 (2018) ICV: 90.90 (2018)

(c) (i) (8)

Copyright@IJCRR

\section{Djurayeva Nafisa, Barakayev Nusratilla, Rakhmonov Kakhramon, Atamuratova Tamara, Mukhamedova Mukhabbat, Muzaffarova Kholida}

Bukhara Engineering Technological Institute, Bukhara, Uzbekistan.

\section{ABSTRACT}

Introduction: Bread and bakery products, due to their high taste and nutritional properties, are in great demand among the population.

Aim and Objective: The study aimed to develop a recipe and technology for the preparation of bakery products from vegetablefat mixtures, balanced in fatty acid composition following modern nutritional requirements for good nutrition. Analyzed the current development priorities of the main sectors of the food industry; identified the most promising of them, in particular, the modification of socially significant food products (fats) by combining them with traditional and non-traditional fat-free oils and low-oil plant raw materials as a source of physiologically functional nutrients. The chemical composition of raw materials has been studied to determine its biological value and food safety. The efficiency of using flour from wheat germ in the composition of vegetable-fat composite mixtures for bakery production has been substantiated.

Method: The experimental part of the work was carried out in the laboratories of the Department of Food Technology of the Bukhara Engineering and Technological Institute and in the accredited complex of the testing laboratory of the Center for Sanitary and Epidemiological Welfare in Bukhara. The research methods traditional for laboratories of food industry enterprises were used. Mixes of flour from wheat germ are offered; animal fat; melted butter; palm, soybean and sunflower oil, balanced in fatty acid content. The expediency of heat treatment of composite mixtures with a flour content from the germ product up to $30.0 \%$ of the mixture mass at a temperature of $40-50{ }^{\circ} \mathrm{C}$, more than $30 \%$ - up to $70{ }^{\circ} \mathrm{C}$ for 10 years. justified 15 minutes, which will increase the degree of its microbiological purity; to reduce the enzymatic action of lipase, protease and embryonic lipoxygenase; extend the shelf life of mixtures up to 45 days.

Result: The optimal dosage of the flour of the germ product was determined to be $70.0 \%$ by weight of the raw materials of the mixtures. The possibility of replacing from 30.0 to $50.0 \%$ of solid fats with vegetable oils has been proven. A positive effect of the developed composites in the amount of up to $5.0 \%$ of the amount of prescription flour on the quality of bread made from 1st-grade wheat flour has been established. Conclusion: The authors consider it expedient to use vegetable-fat mixtures in the production of bakery products from high-quality wheat flour, providing a high consumer value of this type of product.

Key Words: Oils, Bread bakery, Oil raw materials, Combination, Safety, Quality, Vegetable and fat mixtures

\section{INTRODUCTION}

The main elements of modern technology, as a complex production system, are resources. The use of new types of raw materials and products of its processing will significantly expand the World Food Resource due to the involvement in it even of such sources that were not previously considered food. At the same time, food should be enriched only with those nutrients, the deficit of which exists, is widespread enough and dangerous to human health. The effectiveness of fortified foods should be convincingly confirmed by testing on representative groups of people, demonstrating not only their complete safety, acceptable taste, but also good digestibility, the ability to significantly improve the body's supply of physiologically significant nutrients that are introduced into the composition of foods, and indicators associated with these substances. health. Specialized products are used not only in daily nutrition but also in clinical practice for enteral therapy of various pathologies. ${ }^{1}$

The development of innovative resource-saving technologies is carried out by adopting non-traditional, at the same

\section{Corresponding Author:}

Djurayeva Nafisa, Bukhara Engineering Technological Institute, Bukhara, Uzbekistan. Email: qaxa8004@mail.ru

ISSN: 2231-2196 (Print)

Received: 20.07 .2020
ISSN: $0975-5241$ (Online)

Revised: 18.08 .2020
Accepted: 22.09 .2020
Published: 06.10 .2020 
time scientifically grounded technological solutions, while the issues of quality and food safety of products are especially important. Since fatty products occupy a significant sector in the structure of the population's nutrition and are classified as products of mass consumption, the issues of fortification of their functional properties are fully relevant and scientifically substantiated. The production and inclusion in the diet of the population of fats and oils, including fats and oils, useful for health and available to various social strata of the population, is a priority for the development of the food industry.

Currently, the fat-and-oil food industry is at a stage when its development can no longer be carried out by traditional methods, new approaches and solutions are needed to expand the range of products with an improved and balanced fatty acid composition, a high content of fat-soluble vitamins and other biologically active substances. ${ }^{2,3}$

The development of innovative resource-efficient technologies is carried out through the adoption of scientifically grounded technological solutions, for example, the use of non-fatty plant materials to reduce fat content, increase nutritional value and fortify the functional and technological properties of fatty products. At the same time, the issues of quality and food safety of products are very important.

To optimize the fatty acid composition of fatty products, blending of vegetable oils is usually used, including with rather expensive oils or their fractions (vitamins, PUFAs, dietary supplements, phytosterols), dietary fibers, pre- and probiotics), which increases the cost of production and reduces profitability its production. In this aspect, promising is the direction of combinatorics of fats and oils with vegetable raw materials, that is, the creation of vegetable-fat composite mixtures. Their use is especially promising for the development of new types of bakery products, which are the most popular food products.

In this regard, the study of the prospects for the use of new composite mixtures in the baking industry of the food industry is relevant, technologically, socially and economically justified.

\section{MATERIALS AND METHODS}

For the development of new formulations of vegetable-fat mixtures, oil and low-oil raw materials, anhydrous fats, vegetable oils were used.

The aim of the study was to develop new recipes for bakery products with vegetable-fat composite mixtures (here in after RHD), balanced in fatty acid composition following modern nutritional requirements for adequate nutrition, low-fat content.
Research objects. The experimental part of the work was carried out in the laboratories of the Department of Food Technology of the Bukhara Engineering and Technological Institute, an accredited complex of the testing laboratory of the Center for Sanitary and Epidemiological Welfare in Bukhara, Republic of Uzbekistan (accreditation certificate UZ.AMT.07.MAI.493). Production tests were carried out in the production conditions of PASQUALE LLC (Bukhara).

The following raw materials were used in the work: wheat flour of the 1st grade O'zDSt 1104-20011, pressed yeast GOST 171-81, iodized food salt O'zDSt 1091: 2011, vegetable oils O'zDSt 816: 2012, animal fat GOST 25292- 2017, wheat germ flour.

The subject of the research is the technology of production of new types of bakery products from high-quality wheat flour using vegetable-fat smacks to expand the segment of socially significant "healthy food" products.

The objects of the study were samples of bread made from wheat flour of the 1st grade: a comparison sample - using a fatty product without a plant additive, experimental samples - with the addition of vegetable-fat smacks. The dough was prepared with a corresponding correction of the recipe: vegetable-fat smacks was introduced in the amount of 1.0, $3.0,5.0$ and $7.0 \%$ with the replacement of the corresponding amount of flour.

Investigated the microbiological composition of vegetablefat smacks: KMAFAnM according to GOST 10444.15-94 "Food products. Methods for determining the amount of mesophilic, aerobic and facultative anaerobic microorganisms “, GOST R ISO 7218-08" Microbiology of food and animal feed. General requirements and recommendations for microbiological research “, GOST 31747-2012 (ISO 4832: 2006)" Food products. Methods for detecting and determining the number of bacteria of the group of Escherichia coli (coliform bacteria) “, GOST 10444.12-88” Food products. Method for the determination of yeast and molds".

A series of test laboratory baked goods was carried out according to the generally accepted method according to GOST 27669-88 "Wheat baking flour. Method of laboratory baking of bread ". The volumetric bread yield (cm3 / $100 \mathrm{~g}$ of flour) was determined following GOST 27669-88 "Bread and bakery products. Methods for determining the volumetric yield of bread ". The swelling of the bread crumb was determined according to Katz's refined method; crumb crumbness - according to the method developed at MGUPP.

\section{DISCUSSION}

To select the herbal ingredient in the composites, an analysis of the nutritional value of bakery products was performed to identify the most deficient nutrients in them. It was found 
that the daily protein requirement from bread contained in $450 \mathrm{~g}$ of bread products conditionally eaten daily by an adult is covered by $38.0 \%$, including in vegetable protein - by $85.5 \%$, and in certain amino acids - by $23.0 \ldots 58.0$ Sharply not enough due to bakery products the need for lysine $(23.1 \%)$ - the amino acid, which is the most deficient in the global nutritional balance of mankind, is met, as well as cystine - by $24.8 \%$ and methionine - by 18 , five $\%$. The human need for carbohydrates due to flour products, depending on the recipe, is covered (in\%): in starch and dextrins - by 41.0, in ballast substances - by 57.2, and mono- and disaccharides - 17.4 - 40. The daily consumption of flour products satisfies the adult's need for fats by $8.9 \ldots 15.0 \%$, polyunsaturated fatty acids - by $62.0 \%$, phosphatides - by $23.4 \%$. Organic acids satisfy the demand for these acids by $49.5 \%$. Due to bread, 1/4 of the need for vitamin B3 is covered, and for vitamin B2 - only $18.7 \%$. However, wheat flour does not contain retinol (A), calciferol (D2), ascorbic acid (C), vitamin B12. The ash elements of flour products are represented by macro (phosphorus, potassium, calcium, magnesium, sodium, iron) and microelements (copper, manganese, aluminium, cobalt, boron, selenium, bromine, iodine, etc.). It has been established that flour products cover the needs of the human body by almost $47.0 \%$ in such important biogenic trace elements as copper, manganese, zinc, cobalt; $11.5 \%$ - calcium, $45.6 \%$ - phosphorus, $84.7 \%$ - iron.$^{2-4}$

It should be noted that flour with an ash content of less than $0.6 \%$ (premium grade) contains only $29.0 \%$ of the valuable nutritional components of whole wheat grain. Of the 28 vital elements of wheat, 9 disappear completely. Among them are anticarcinogenic selenium, hematopoietic vanadium and titanium; the mass fraction of calcium decreases to 19.0 from 60.0, iron - 1.86 from 5.38, manganese - 0.86 from $3.86 \mathrm{mg}$, etc. Vitamin E (tocopherol) in such flour is completely absent, negligible proportions of vitamins of group B remain, and the most important dietary fibers (fiber) leave in the bran, while its calorie content increases. Flour loses 25.0 $30.0 \%$ of protein. The constant use of bread made from fine flour leads to dysfunction of the gastrointestinal tract, urolithiasis, diabetes, anaemia, obesity. The most valuable flour is considered to be made from the endosperm, aleurone layer and shells, which makes up about $97.0 \%$ of the grain weight. However, bread made from such flour contains phytic acid, which hinders the absorption of calcium, iron and other minerals, which contributes to the development of rickets, anaemia, and dysfunction of the thyroid gland. ${ }^{4}$

It was found that the main problems associated with the formation of the quality of bakery products in dynamic production conditions are solved through the use of various additives of non-alimentary origin, which alarms consumers and nutritionists, since, taking into account the volume of consumption of these products, even an insignificant content of potentially hazardous chemical compounds in them nature exerts a certain pressure on the human body, which is one of the most important risk factors for his health. ${ }^{5}$

Recently, considerable attention has been paid to the development of new types of bakery products with the maximum possible use of grain components. For example, in the UK and France, the demand for healthy whole grain bread has increased. In Germany, special varieties of bread have been developed with the addition of other cereal products of special grinding, products of animal or vegetable origin. ${ }^{6}$

Therefore, we paid special attention to the products of grain processing, as a potential raw material for the production of vegetable-fat smacks.

As a plant fraction of vegetable-fat smacks, it seems expedient to use wheat germ and other grain crops, in particular, rye and corn, as well as bran from rice and millet. In terms of fatty acid composition, oil lipids extracted from the embryos of grain crops are close to storage lipids of oil plants. With the complex use of this type of low-oil raw material, it is possible to obtain edible vegetable oil, fodder meal rich in easily digestible protein groups and essential amino acids, as well as vegetable waxes.

Wheat germ products deserve special attention, the oil of which is distinguished by a balanced fatty acid composition in terms of the ratio of polyunsaturated fatty acids (PUFA) of the $\omega-6$ and $\omega-3$ classes. Wheat germ triacylglycerides contain a significant amount of $\omega-3$ acid, which is practically absent in many widespread vegetable oils and fats. Wheat germ is a source of tocopherols, provitamin A, high-value protein, macro- and microelements, which testifies to their properties as a prescription ingredient, improve the quality, increase the nutritional and biological value of food. It should be noted that the extraction of oil from the embryos is a laborious process with a very low yield. Besides, in practice, one has to deal not with "pure" wheat germs, but with the so-called wheat germ product (WG), usually consisting of $60-65 \%$ of wheat germs and $35-40 \%$ of bran, flour, fragments of endosperm and aleurone layer. ${ }^{7}$

The unique composition of germ products, despite the low oil content (13-15\%), actualizes its processing into fractions for further use in various industries. However, due to the low stability of quality during storage, many problems arise when using this product. Therefore, serious attention is paid to finding ways to increase the shelf life of the salary. So, Tarutin increased the shelf life of germ products by exposure to infra-red rays in the temperature range of 50 $-100^{\circ} \mathrm{C}^{8,9}$. Degreasing of germ products with a hydraulic press up to $4.0 \%$ and subsequent grinding was suggested by Grandel. ${ }^{10}$ Vedernikova and others carried out the processing of germ products with flowing steam at atmospheric air pressure. ${ }^{11}$ The known technology of freezing germ products at low temperatures, while the storage period increased to 16 
weeks. ${ }^{8}$ One of the promising directions for increasing the shelf life of the saline is the use of preservatives (fumaric, ascorbic). Treatment with antioxidants (5-pentadecylresorcinol) in the amount of $0.01-0.50 \%$ by weight of the product was carried out by Barnes et al. Gaver investigated the effect of epoxy compounds on the RF to increase the shelf life up to six months at a temperature of $20-25^{\circ} \mathrm{C} .{ }^{12,13}$

However, these methods are not cost-effective due to the high energy consumption, while irreversible negative processes in the product also occur.

Of particular interest is the possibility of using crushed ZP as a flour fraction of RHD, where the fatty component, especially if it is anhydrous, is capable of exerting a certain preserving effect during storage. It is possible to use these mixtures as alternative substitutes for fats in the production of flour products.

Comparative analysis of the chemical composition of flour from wheat ZP (hereinafter MWP) and wheat flour of the 1 st grade showed that the mass fraction of protein and fat in the MWP is on average 2.4 and 7.8 times higher than similar indicators in the flour of the 1st grade, respectively. In the MZP, on average, 4.0 times more iron than in the reference sample, an increased amount of fiber. Significant differences were also found in the content of vitamins. Thus, the total amount of vitamins in the MWP is almost 8.0 times more than in flour. Sucrose and raffinose dominate among MWP carbohydrates; there are also starch and fiber due to the presence of endosperm fragments and membranes in the product. The energy value of the MWP exceeds the same value for the reference sample by $8.4 \%$.

It is also important that the protein of wheat germ in terms of the content of the most deficient amino acids such as lysine, methionine and tryptophan is similar to egg protein, which is a sign of good digestibility of this product. It was found that the limiting amino acids of MWP are methionine and cystine. The mass fraction of the amino acid lysine, which is the most deficient in the world nutritional balance of mankind, is 2.3 times higher than that in the reference sample.

Wheat germ oil holds the record for the content of tocopherols, while its most active forms prevail in it - $\alpha$ - tocopherol, and the total amount of $\beta-, \gamma-, \sigma$-tocopherols - $93 \mathrm{mg}$ $\%$, tocopherol - acetate $-83 \mathrm{mg} \%$. The phytosterol fraction of the oil (1.2 .. $1.6 \mathrm{mg} \%)$ contains sitosterol, campesterol, ergosterol, brassicasterol, stigmasterol, desmosterol, and neoergosterol. The oil is used mainly as a dietary supplement for food, which can improve the lipid spectrum of the blood and have a strong antioxidant effect in the body. ${ }^{14,}$ ${ }^{15}$ It has been found that wheat germ has a hypoallergenic effect and is an environmentally friendly product. With the complex use of this type of oilseed raw material, it is possible to obtain flour, fodder meal, rich in easily digestible protein groups and essential amino acids, as well as vegetable waxes. ${ }^{16,17}$

As an alternative to ZP, you can use pseudo-grains, in particular amaranth or shiritsa. ${ }^{13}$ The total protein of amaranth seeds by $28.0-35.0 \%$ consists of essential amino acids. In terms of lysine content, amaranth protein is twice as large as wheat protein. The nutritional value of amaranth seeds for lysine reaches $118.0 \%$, while in most cereals this figure is less than $50.0 \%$, the lipid fraction contains up to $10.0 \%$ squalene. Also, amaranth is rich in iron, phosphorus, potassium, vitamins B1, B2, E, group D, phospholipids, phytosterols. The composition of amaranth oil contains more than $70.0 \%$ of mono- and polyunsaturated fatty acids: linoleic $(\omega-6)$, oleic $(\omega-9)$, linolenic $(\omega-3)$, arachidonic, palmitoleic acids, etc., more than $9,0 \%$ phospholipids (in which phosphatidylcholine dominates in terms of quantity), squalene (more than $8.0 \%$ ), about $2.0 \%$ of vitamin $\mathrm{E}$, phytosterols (over $2.0 \%$ ), carotenoids (precursors of vitamin A), vitamin D, bile acids, various macro- and microelements (potassium, iron, phosphorus, calcium, magnesium, copper, etc.). The unique healing properties of amaranth oil are largely determined by the presence in its composition of two powerful antioxidants - squalene and vitamin E, which is contained in amaranth oil in a rare, particularly active tocotrienolic form. However, anti-nutritional substances were also found in the composition of amaranth: a trypsin inhibitor and tannins, which are present in small amounts $(0.06 \%)$ and are effectively inactivated during moisture-heat treatment.

Also noteworthy is the meal obtained after extracting oil from sunflower seeds and characterized by high protein content $(44.0 \ldots 47.0 \%)$. The main protein of sunflower seeds helianthin - is ILS-globulin, which contains a lot of glutamic (26.0\% of the total amino acids) and aspartic acids (14.0\%), as well as arginine $(9.7 \%)$. It should be noted that the production of edible sunflower protein is complicated by the presence of chlorogenic acid and other phenolic compounds in it, which cause browning of products during heat treatment. The content of phenolic compounds in sunflower meal ranges from 3.0 to $3.5 \mathrm{~g}$ per $100 \mathrm{~g}$ of skim flour. Of these, up to $70.0 \%$ are chlorogenic and caffeic acids, up to $15.0 \%$ are compounds like n-coumarilic, isoferulic and synapse acids, as well as esters of hydroxycinnamic acid. Protein isolates proteins isolated from the meal with the help of weak alkali solutions, along with the indicated acids, contain neoisochlorogenic acid. Under the action of flour polyphenol oxidase, chlorogenic acid is converted into quinones, which form dark-coloured compounds of unknown composition. The presence of inhibitors of proteolytic enzymes in the meal negatively affects the digestibility of protein in the body of animals, causing hypertrophy of the pancreas, a decrease in the proteolytic activity of the small intestine, impairment of amino acid absorption and growth retardation of animals. Sunflower oil belongs to valuable vegetable oils, has good 
organoleptic properties - amber-golden colour, rich taste, is well absorbed by the human body - by $83.0 \%$. It consists mainly of oleic and linoleic acid glycerides; unrefined oil contains up to $1400 \mathrm{mg} \%$ phospholipids, up to $300 \mathrm{mg} \%$ sterols. Sunflower oil has a high E-vitamin activity, contains mainly alpha-tocopherol - up to $60 \mathrm{mg} \%$, is rich in vitamins B1, B2, PP; contains scopoletin, a coumarin compound with antispasmodic and hypoglycemic activity. Sunflower seeds are a rich source of magnesium (317 mg\%). ${ }^{14,18}$

Sesame or sesame seeds are the most economical and valuable agricultural raw material due to their unique chemical composition. They contain fatty oil (up to $60.0 \%$ ), which includes glycerides of oleic, linoleic, palmitic, stearic, arachidic and lignoceric acids; phytosterol, sesamin, sesamol, sesamolin, samam, and are also rich in calcium, phosphorus, vitamin $\mathrm{E}$, iron, magnesium and zinc. It was found that the seeds of this culture contain (\%): moisture - 5.7, proteins 20.0, ash - 3.7, fiber - 3.2, fat - 54.0 and carbohydrates - 13.4. They contain (in $\mathrm{mg} / 100 \mathrm{~g}$ ): a lot of potassium (851, 35 \pm 3.44 ), phosphorus $(647.25 \pm 3.52)$, magnesium $(579.53 \pm$ $0.42)$, calcium $(415.38 \pm 3.14)$ and sodium $(122.50 \pm 4.21)$. The seeds are rich in manganese, copper, and calcium, contain vitamins B1 and E. Phytosterols are also found in sesame seeds, which block cholesterol. In medicine, sesame oil is considered as a plant component that helps prevent the development of various diseases, including cancer. ${ }^{18,19}$

Seeds are waste in the processing of melon fruits . Chemical composition of seeds (\% in terms of dry matter): water -6 6.2; lipids - 25-26.5; protein - 22.5-25.5; starch and soluble sugars - 10-11; pentosans - up to 8.0; cellulose - 20-21.4; ash - 2.5-3.0. The kernel contains up to $50 \%$ oil, and the husk $0.5-0.6 \%$. Melon seed oil, edible, light yellow. Oilcake and meal contain $32-46 \%$ protein and are valuable fodder. ${ }^{18}$

The use of tomato seeds as an additive in food production seems to be very promising. However, tomatoes, like other members of the Solanaceae family, are characterized by the presence of toxic alkaloids. Alkaloids are localized mainly in the skin of the fruit (10.0\%). When juice, sauces, tomato puree and tomato paste are produced from the fruits of tomatoes, pomace is obtained, which is a mixture of seeds, fruit skin and minor pulp residues. Freshly obtained pomace contains a large amount of moisture (40-45.0\%) and is practically non-transportable. The storage of such pomace, even for the shortest time, leads to a sharp deterioration in the oil contained in the seeds. Seeds are isolated from pomace and dried to a moisture content of $11-12.0 \%$. The chemical composition of tomato seeds (\%): water $-7-8$, lipids $-25-35$, protein $-25-30$, cellulose -16-25, ash - 2.4-3. Tomato seeds produce a light yellow to a dark brown oil, sometimes with a more intense reddish colour due to the high content of carotenoids. It has a pungent peppery odour and contains 0.8 $1.0 \%$ phospholipids, $112-150 \mathrm{mg}$ per $100 \mathrm{~g}$ of tocopherols, up to $1.0 \%$ carotenoids and $0.8-1.88 \%$ other unsaponifiable lipids. The oil is used for food and technical purposes. Lowfat seeds are used for livestock feed. ${ }^{18,20}$

Rapeseed cake and meal in terms of energy value (11.3 and $10.4 \mathrm{MJ}$ of exchangeable energy) is not inferior to sunflower cake (11.4 and $10.6 \mathrm{MJ}$, respectively). In terms of calcium, phosphorus, magnesium, copper and manganese content, rapeseed meal and meal are superior to soybean meal. The availability of calcium in them is $68.0 \%$, phosphorus $-75.0 \%$, magnesium - $62.0 \%$, manganese $-54.0 \%$, copper $-74.0 \%$, zinc $-44.0 \%$. Rapeseed meal contains significant amounts of choline, niacin, riboflavin, folate and thiamine. The disadvantage of rapeseed oil is the high content of erucic acid in it: our enzymes cannot utilize it, and therefore it accumulates in the body, which can cause delayed sexual development in children. Also, erucic acid can be dangerous for the liver, heart, skeletal muscles and blood vessels; therefore, some varieties of rapeseed oil in some countries, including the European Union, are prohibited for use as a food product. ${ }^{21,22}$

In recent years, the raw material base has expanded due to the use of secondary oilseeds obtained at canning factories, namely, fruit (fruit) seeds of apricot, peach, plum, cherry, almond, etc.

Nevertheless, in terms of production volume, cost price and availability, it is most expedient to use the minimum wage as part of the RHD. The large scale of modern flour-and-cereal production makes it possible to concentrate these products in a significant volume.

Products of complex processing of wheat germ have ideal technological properties: yellowish colour, with a pleasant taste and smell, relatively high water-binding capacity, which opens up wide possibilities for their introduction into any food system. So, in the State Research Institute of the Bakery Industry, developments were carried out on the use of products of complex processing of wheat grain in recipes for bakery and flour confectionery products. The use of MZP is recommended in the formulations of easily digestible gingerbread cookies, cookies, various cakes, wafers both for healthy people involved in physical education and sports, and for patients with diabetes mellitus, cardiovascular diseases, renal pathologies, or during the period of postoperative rehabilitation of patients.

The technological disadvantage of the widespread use of wheat germ is the instability of their properties during storage. Therefore, a certain interest is aroused by the possibility of using this product as a vegetable component of composite mixtures with anhydrous fats. The lack of moisture and oxygen has a microstatic effect on the saprophytic microflora of grain and storage mould, while the lipolytic activity of bacteria, filamentous fungi and individual yeasts decreases. Under anaerobic conditions, the activity of enzymes that catalyze the oxidation of unsaturated fatty acids with atmospheric 
oxygen decreases with the subsequent formation of peroxide and hydroperoxide compounds, which impart rancid taste and an unpleasant odour to the fat.

Currently, this most valuable natural product, together with bran, is massively used, mainly in the composition of feed for livestock, while fortification of wheat flour and other socially significant food products (fatty products, bakery and confectionery products, etc.) biologically active nutrients are mainly produced at the expense of drugs and additives of a non-alimentary (synthetic) nature, often possessing mutagenic and co-mutagenic properties, the physiological effect of which on the human body has not yet been sufficiently studied.

It should be noted that for the blending of vegetable oils, germ oil is used, the extraction process of which is very laborious at a very low yield (no more than $2.0 \%$ during pressing; the extracted oil is not suitable for food purposes), which significantly increases its cost. Consequently, the wheat germ product, characterized by polyfunctional properties, is a promising biologically valuable ingredient for enrichment with physiologically significant essential and minor nutrients of basic food products intended for the prevention of alimentary-dependent diseases and health promotion of various population groups.

To develop scientifically substantiated requirements for the functional and technological indicators of mixtures, a differentiated approach to the technology of their use in the production of new types of functional products, new formulations of composites and to identify areas of their application, it is necessary to conduct fundamental and applied research.

The development of new technologies for combined food products based on domestic plant raw materials is a priority area of the food industry technologists and is aimed at improving nutritional value, rational use of local raw materials, saving traditional raw materials and increasing the availability of products for the general population. Vegetable raw materials are a source of natural biologically valuable substances, using it you can create products of preventive and health-improving orientation, which guarantees optimal psychophysiological adaptation to ecologically unfavourable environmental conditions.

Thus, the urgency of the problem of creating vegetable-fat composites to increase the physiologically functional significance of food products has been scientifically substantiated. The rational use of secondary products of wheat grain processing, which is a strategic raw material, in the composition of vegetable-fat composite mixtures creates prerequisites for diversification of production, resource conservation and additional profit. Research in this area is technologically and economically justified and has scientific and practical significance.

\section{RESULT}

Various versions of composite mixtures of flour germ foods and animal fat (LF) have been developed; butter ghee (STM); palm (PM), soy (MS), sunflower (MP) oils; RHD. The reference samples were the fatty product (FSP) and MWP.

The results of the study are shown in table 1 and 2 .

The calculation and analytical method were used to determine the content of fatty acids and their ratio in anhydrous compositions (Table 1).

Analysis of the data in Table 1 showed that compositions containing only solid fats (PM, LJ, STM) and flour germ foods (variants 1-3) were distinguished by an increased content of saturated fatty acids (SFA) and a lower content of polyunsaturated fatty acids (PUFA). The ratio of $\omega-6$ and $\omega-3$ PUFAs in mixtures with STM and LJ, which at first glance seems to be acceptable for therapeutic nutrition, against the background of a clear deficiency of PUFA has no significant physiological significance.

The introduction of fatty products with a high content of PUFAs into the dough, which is capable of forming peroxide compounds under the action of flour lipoxygenase, can fortify the oxidation of the sulfhydryl groups of the protein-proteinase complex of flour in the dough and thereby improve the structural and mechanical properties of the dough. When choosing RHD components for the production of flour products, the expediency of the presence in liquid fatty products of a solid crystalline phase was also taken into account, having a melting point higher than the temperature of the dough before baking.

Complete replacement of solid fats with liquid vegetable oils is also not possible due to the sedimentation of particles of the flour component. In this regard, from 30.0 to $50.0 \%$ of hard fats in RHD were replaced with vegetable oils. As a result, the proposed compositions were characterized by relatively optimal ratios of EFA: MUFA: PUFA and $\omega-6: \omega-3$ (4-6 options). Moreover, the dynamics of changes in these data with an increase in the proportion of MW in the compositions indicates the significant role of the latter in the optimization of FS when combined with fats and vegetable oils. Variants 7 and 8 with 60.0 and $70.0 \%$ of the minimum wage differed in the most balanced composition of fatty acids.

To preserve the native properties of MSP as much as possible during mixing, it is desirable to use a gentle temperature regime, however, it is also necessary to ensure a sufficient degree of microbiological purity. Therefore, when obtaining RZhS, the heat treatment was carried out during mixing with the fat component heated to $70^{\circ} \mathrm{C}$ for $10-15$ minutes. The fatty component was cooking oil.

Investigated the microbiological contamination of the studied compositions by conventional methods of inoculation on 
specialized media. The samples were stored for 90 days at a temperature of $37 \pm 20 \mathrm{C}$. Their microbiological contamination and compliance with the requirements of sanitary rules and norms were checked monthly. The research results are shown in Table 2.

It should be noted that in the studied composites after 60 days of incubation on Endo's medium (Levin's medium or bismuthsulfite agar), no groups of Escherichia coli bacteria were found; therefore, further inoculations were not performed. Inoculations on Sabouraud's medium for detecting fungi and yeasts showed that they were not detected in all heat-treated samples after 60 days and in a composition with an MWP content of $30 \%$ without heat treatment after 30 days. It was found that in the variants of mixtures with 30,50 and $70.0 \%$ of the MWP, not subjected to heat treatment, the initial number of microorganisms naturally increased, respectively, 157, 217 and 307 CFU / g.
The increase in the biomass of microflora during the storage period (90 days) increased by an average of 3.8 times, the content of molds in the variants with heat treatment is on average 2.3 times less than in similar samples without heat treatment. All variants with heat treatment at the end of the test period of storage had indicators of the microbial ecosystem within acceptable limits.

The proposed method for producing RZhS provides for melting the fat fraction with the introduction of flour with constant stirring. It should be borne in mind that when obtaining composites with an MWF content of up to $30.0 \%$, it is advisable to temper the mixture with anhydrous fat at a temperature of $40-50{ }^{\circ} \mathrm{C}$, more than $30.0 \%$ - up to $70{ }^{\circ} \mathrm{C}$. Duration of tempering 10-15 $\mathrm{min}$. The recommended shelf life is 45 days.

\section{Table 1: The ratio of fatty acids in anhydrous compositions of solid fats, oils and MZP}

\begin{tabular}{|c|c|c|c|c|c|c|c|c|c|c|c|c|c|c|c|}
\hline \multirow[t]{4}{*}{ № } & \multirow{2}{*}{\multicolumn{2}{|c|}{$\begin{array}{l}\text { The mass } \\
\text { fraction in } \\
\text { the mix- } \\
\text { ture, } \%\end{array}$}} & \multirow{4}{*}{ 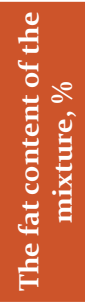 } & \multicolumn{12}{|c|}{ The ratio of fatty acids in the fat phase of the mixture } \\
\hline & & & & \multirow{2}{*}{\multicolumn{2}{|c|}{$\mathbf{J j}+\mathbf{F}_{\mathrm{GP}}$}} & & \multicolumn{2}{|c|}{$\mathrm{PM}+\mathrm{F}_{\mathrm{GP}}$} & \multirow{2}{*}{\multicolumn{2}{|c|}{$\begin{array}{c}\mathrm{Jj} \\
(50 \%)+\mathrm{PM}(25 \%)+ \\
+\mathrm{MS}(25 \%)+\mathrm{F}_{\mathrm{GP}} \\
4\end{array}$}} & \multirow{2}{*}{\multicolumn{2}{|c|}{$\begin{array}{c}\operatorname{STM}(50 \%)+\mathrm{MP} \\
(25 \%)+ \\
+\mathrm{MS}(25 \%)+\mathrm{F}_{\mathrm{GP}} \\
5\end{array}$}} & \multirow{2}{*}{\multicolumn{2}{|c|}{$\begin{array}{c}\operatorname{PM}(70 \%)+\mathrm{MS}(30 \%)+ \\
\mathrm{F}_{\mathrm{GP}} \\
6\end{array}$}} \\
\hline & & & & & & 2 & & 3 & & & & & & & \\
\hline & ZhPr. & $\mathbf{M}_{\mathrm{zp}}$ & & $\begin{array}{c}\text { NLC: } \\
\text { MNFA: } \\
\text { PUFA }\end{array}$ & $\begin{array}{l}\omega-6: \\
\omega-3\end{array}$ & $\begin{array}{c}\text { NLC: } \\
\text { MNFA: } \\
\text { PUFA }\end{array}$ & $\begin{array}{l}\omega-6: \\
\omega-3\end{array}$ & $\begin{array}{c}\text { NLC: } \\
\text { MNFA: } \\
\text { PUFA }\end{array}$ & $\begin{array}{c}\omega-6: \\
\omega-3\end{array}$ & $\begin{array}{c}\text { NLC: } \\
\text { MNFA: } \\
\text { PUFA }\end{array}$ & $\begin{array}{c}\omega-6: \\
\omega-3\end{array}$ & $\begin{array}{c}\text { NLC: } \\
\text { MNFA: } \\
\text { PUFA }\end{array}$ & $\omega-6: \omega-3$ & $\begin{array}{c}\text { NLC: } \\
\text { MNFA: } \\
\text { PUFA }\end{array}$ & $\omega-6: \omega-3$ \\
\hline 1 & 100 & $\mathrm{o}$ & 100 & $55: 40: 5$ & $2,8: 1$ & $62: 33: 5$ & $2,6: 1$ & 49:40:11 & - & $35: 32: 33$ & $10,2: 1$ & $39: 28: 33$ & 10,0:1 & $40: 34: 26$ & $8,5: 1$ \\
\hline 2 & 90 & 10 & 91 & 55:40:5 & 3,0:1 & $62: 33: 5$ & 2,9:1 & 48:40:12 & $156: 1$ & $35: 32: 33$ & 10,1:1 & $39: 28: 33$ & 9,9:1 & $39: 34: 27$ & $8,5: 1$ \\
\hline 3 & 80 & 20 & 82 & 54:40:6 & 3,2:1 & $61: 33: 6$ & $3,2: 1$ & 48:39:13 & $74: 1$ & $35: 31: 34$ & $10,0: 1$ & $39: 28: 33$ & 9,9:1 & $39: 34: 27$ & $8,4: 1$ \\
\hline 4 & 70 & 30 & 73 & 53:39:8 & 3,8:1 & $60: 33: 7$ & $3,4: 1$ & 47:39:14 & $46: 1$ & $35: 31: 34$ & 9,9:1 & $38: 28: 34$ & 9,8:1 & $39: 33: 28$ & $8,4: 1$ \\
\hline 5 & 60 & 40 & 64 & $53: 39: 8$ & $4,2: 1$ & $59: 33: 8$ & 4,0:1 & $46: 39: 15$ & $32: 1$ & $34: 31: 35$ & $9,8: 1$ & $37: 28: 35$ & $9,7: 1$ & $38: 33: 29$ & $8,4: 1$ \\
\hline 6 & 50 & 50 & 55 & 51:39:10 & $4,6: 1$ & $58: 32: 10$ & 4,4:1 & $46: 38: 16$ & 24:1 & $34: 31: 35$ & $9,7: 1$ & $37: 27: 36$ & $9,6: 1$ & $38: 33: 29$ & 8,3:1 \\
\hline 7 & 40 & 60 & 46 & $50: 38: 12$ & $5,1: 1$ & $56: 32: 12$ & 4,9:1 & $45: 37: 18$ & $19: 1$ & 33:30:37 & $9,5: 1$ & $36: 27: 37$ & $9,4: 1$ & $37: 32: 31$ & 8,3:1 \\
\hline 8 & 30 & 70 & 37 & 48:37:15 & $5,6: 1$ & 54:31:15 & $5,5: 1$ & $43: 36: 21$ & $15: 1$ & $32: 30: 38$ & $9,3: 1$ & $35: 27: 38$ & $9,2: 1$ & $35: 31: 33$ & $8,2: 1$ \\
\hline
\end{tabular}

Table 2: Changes in the composition of the microbial ecosystem in the RHD during storage

\begin{tabular}{|c|c|c|c|c|c|c|c|c|c|c|}
\hline \multirow[t]{2}{*}{$\begin{array}{l}\text { Term incubation, } \\
\text { days }\end{array}$} & \multicolumn{2}{|c|}{$\begin{array}{l}\text { KMAFanM, } \\
\text { CFU / g }\end{array}$} & \multicolumn{2}{|c|}{$\begin{array}{c}\text { Yeast }\left(\times 10^{3}\right), \text { CFU } \\
/ \mathrm{g}\end{array}$} & \multicolumn{2}{|c|}{$\begin{array}{c}\text { Moldy } \\
\text { mushrooms }\left(\times 10^{2}\right) \\
\text { CFU / g }\end{array}$} & \multicolumn{2}{|c|}{$\begin{array}{l}\text { Bacteria } \\
\text { E.coli, } \\
\text { CFU / g }\end{array}$} & \multicolumn{2}{|c|}{$\begin{array}{l}\text { Compliance with the } \\
\text { requirements } \\
\text { San PiN o138- } 03\end{array}$} \\
\hline & $1^{*}$ & $2^{*}$ & 1 & 2 & 1 & 2 & $\mathbf{1}$ & 2 & 1 & 2 \\
\hline \multicolumn{11}{|c|}{ Experience with $30 \% F_{\mathrm{GP}}$} \\
\hline o & $157 \pm 5,0$ & $68 \pm 5,6$ & - & - & - & - & $\mathrm{H} / \mathrm{O}^{*}$ & $\mathrm{H} / \mathrm{O}$ & acc. & acc. \\
\hline 30 & $203 \pm 5,6$ & $122 \pm 5,0$ & - & - & - & - & $\mathrm{H} / \mathrm{O}$ & $\mathrm{H} / \mathrm{O}$ & acc. & acc. \\
\hline 60 & $448 \pm 5,2$ & $196 \pm 5,2$ & - & - & $0,2 \pm 0,1$ & - & - & - & acc. & acc. \\
\hline 90 & $646 \pm 6,6$ & $275 \pm 5,3$ & $0,4 \pm 0,1$ & $0,2 \pm 0,1$ & $0,5 \pm 0,1$ & $0,2 \pm 0,1$ & - & - & acc. & acc. \\
\hline \multicolumn{11}{|c|}{ Experience with $50 \% F_{\mathrm{GP}}$} \\
\hline o & $217 \pm 5,0$ & $102 \pm 6,5$ & - & - & - & - & $\mathrm{H} / \mathrm{O}^{*}$ & $\mathrm{H} / \mathrm{O}$ & acc. & acc. \\
\hline 30 & $465 \pm 5,6$ & $194 \pm 6,2$ & $0,3 \pm 0,1$ & - & - & - & $\mathrm{H} / \mathrm{O}$ & $\mathrm{H} / \mathrm{O}$ & acc. & acc. \\
\hline 60 & $668 \pm 5,2$ & $242 \pm 6,0$ & $0,7 \pm 0,1$ & - & $0,6 \pm 0,1$ & - & - & - & acc. & acc. \\
\hline 90 & $848 \pm 6,6$ & $350 \pm 6,3$ & $1,1 \pm 0,1$ & $0,5 \pm 0,1$ & $1,3 \pm 0,1$ & $0,6 \pm 0,1$ & - & - & not acc. & acc. \\
\hline \multicolumn{11}{|c|}{ Experience with $70 \% F_{\mathrm{GP}}$} \\
\hline $0 \quad 30$ & 56,2 & $179 \pm 7,0$ & - & - & - & - & $\mathrm{H} / \mathrm{O}^{*}$ & $\mathrm{H} / \mathrm{O}$ & acc. & acc. \\
\hline $517 \pm$ & & $218 \pm 7,5$ & $0,4 \pm 0,1$ & - & - & - & $\mathrm{H} / \mathrm{O}$ & $\mathrm{H} / \mathrm{o}$ & acc. & acc. \\
\hline 898 & & $324 \pm 7,8$ & $0,9 \pm 0,1$ & - & $0,9 \pm 0,1$ & - & - & - & acc. & acc. \\
\hline 1082 & & $436 \pm 8,1$ & $1,5 \pm 0,1$ & $0,7 \pm 0,1$ & $1,7 \pm 0,1$ & $0,8 \pm 0,1$ & - & - & not acc. & acc. \\
\hline
\end{tabular}

* Note: 1- samples prepared without heat treatment; 2 - samples subjected to heat treatment; $\mathrm{n}$ / a - not found; acc. complies with sanitary requirements and standards. 
The proposed method of using a non-fat-free germ product as part of an RHD will make it possible to use $100 \%$ of the oil content of this raw material, reduce the amount of fat, increase the nutritional value and reduce the cost of the final product.

The baking data showed that the dosage of RZhS in an amount of $5.0 \%$ by weight of flour with an MWP content of up to $50.0 \%$ contributes to obtaining products of the required quality. A further increase in the dosage of the mixture led to a decrease in the intensity of gas and acid formation, a slowdown in the ripening process of flour semi-finished products and, as a consequence, the production of products of a reduced volume with an insufficiently developed structure of crumb porosity.

In the variants with the studied additives up to $5.0 \%$ to the flour mass, an increase in the value of the porosity index of bread relative to the reference sample was found, on average, by $1.3-8.4 \%$, the volumetric yield - by $0.8-7.2 \%$, improved form-holding capacity of hearth bread samples. With a further increase in the dosage of RZhS, a decrease in the values of these indicators was noted (Fig. 1).

The prototypes of bread for $4-6$ hours more retained signs of freshness. There was an increase in the swelling of the crumb of bread during storage by $2.5-9.6 \%$ and a decrease in the degree of its crumbliness - by $1.4-8.5 \%$ concerning the control (Fig. 2).

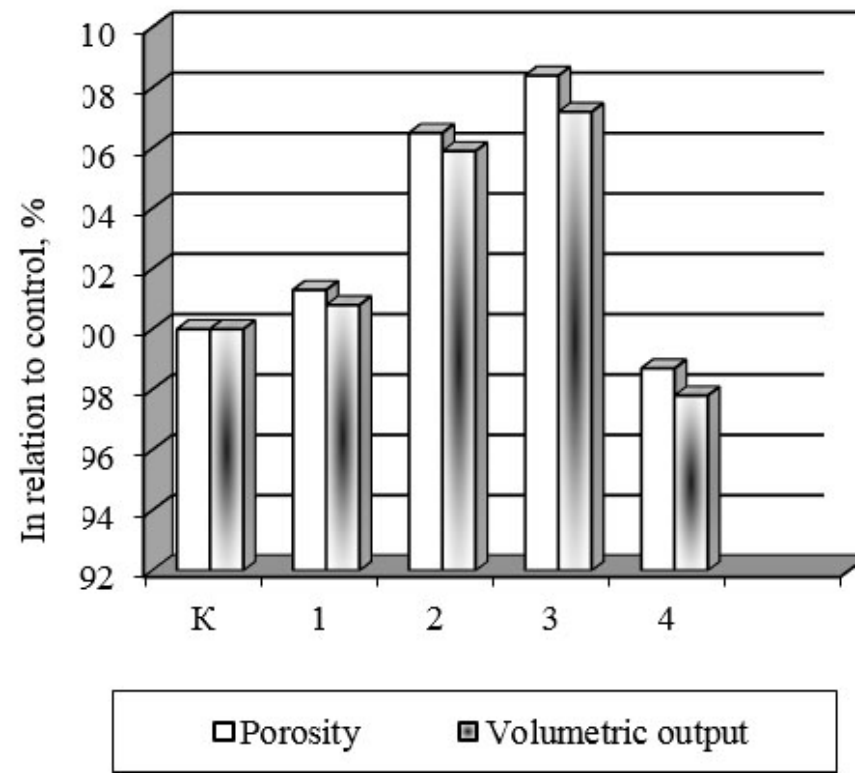

Figure 1: Influence of RHD on the porosity and volumetric yield of bread from wheat flour of the 1st grade according to the options.

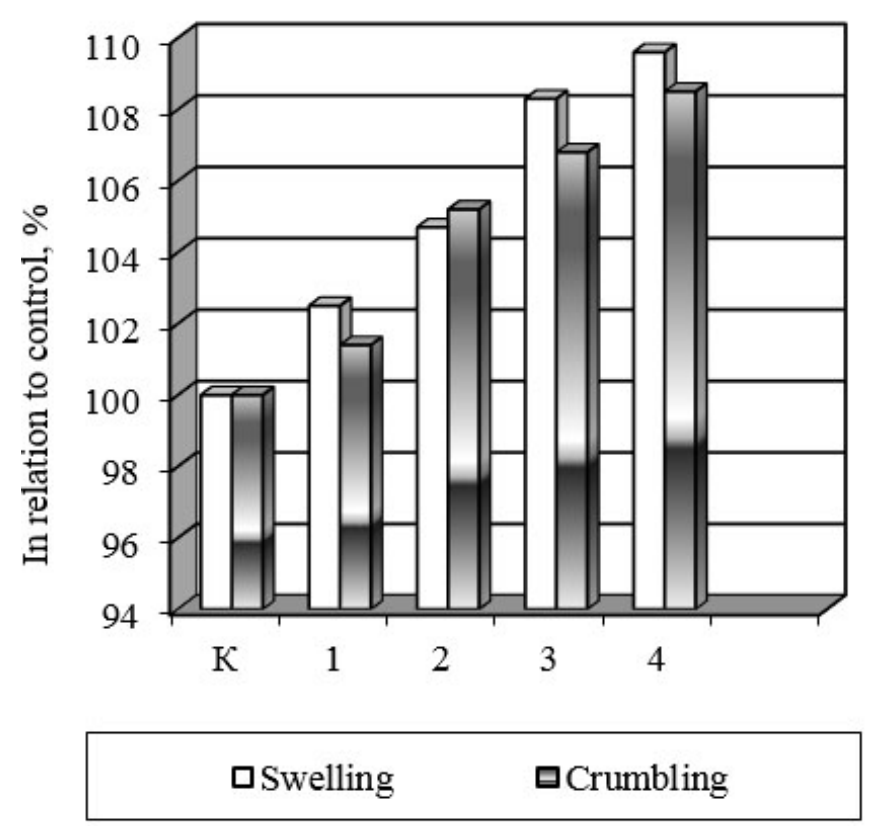

Figure 2: Influence of RHD on the swelling and crumbiness of bread made from wheat flour of the 1st grade according to options after 48 hours of storage.

$\mathrm{K}$ - without $\mathrm{F}_{\mathrm{GP}} ; 1-1 ; 2-3 ; 3-5,4-7,0 \% \mathrm{FFM}$ to the mass of flour

The results of the studies carried out indicate the efficiency of using RHD with MWP in an amount of up to 5.0\% to the prescription amount of high-quality wheat flour, which contributes to the rational use of valuable food raw materials and an improvement in the quality indicators of finished products.

\section{CONCLUSION}

Thus, it was found that a promising functional ingredient of RHD for the production of flour products is oil and low oil raw materials. At the same time, in terms of production volume, biological value, functional and technological properties, food safety and relatively low-cost price, special attention should be paid to the wheat germ product, the potential of which has not yet been sufficiently studied, especially when creating vegetable-fat composite mixtures with a balanced fatty acid composition for the intended purpose. The large scale of modern flour-and-cereal production makes it possible to concentrate these products in large quantities. When properly collected and stored, they represent a significant additional source of natural biologically valuable nutrients.

It should be noted that fatty products are especially in demand in the bakery food industry. At the same time, the food industry is more and more in need of fortified fatty products of solid consistency, which, by their technological proper- 
ties, would be suitable as the main biologically valuable structuring component of margarine, bakery and confectionery products. The use of mixtures with a predictable biopotential, having the appropriate functional and technological properties and biological value, combining high efficiency, manufacturability and harmlessness, can provide the required product quality and increased stability during storage. The use of non-fat-free oil and low-oil raw materials as a vegetable component in RHD will significantly expand the range of fatty products for targeted purposes.

The advantage of using wheat germ products in the composition of composites with fats is also that they are traditional natural food raw materials, the use of which does not require significant changes in the technological process of production of new products allows the maximum use of biologically active nutrients while maintaining their native properties, creates preconditions for the diversification of both grain processing and fat-and-oil industries. The use of this raw material, and not just oil from it, will allow 100\% use of the botanical oil content of the embryos; to reduce at their expense the prescription amount of individual fatty components; increase the nutritional value of products and reduce their calorie content. It is advisable to use vegetable and fat compositions as an alternative to traditional fats in the production of flour products, which is what is technologically efficient.

\section{REFRENCES}

1. Mulina NA, Yevstigneyeva NI. and Yurikov YA, The problem of insufficient status nutrition and its solving methods. Storage and processing of farm products, 2006; 6: 71-72.

2. Matveeva TV, and Koryachkina SY. Flour pastry functional appointment. Scientific facts, technologies, receptions: monograph. Orel: FGBOU VPO “State University-NPK”, 2011: 358.

3. Kukharenko AA, Bogatyryov AN, Kotorkiy VM, and Dadashev MN. Scientific principles of enriching foodstuffs with micronutrients. Food processing industry, 2008; 5: 62-66.

4. Koryachkina, SY, Berezina NA, and Goncharov YV. The innovative technology of bakery, macaroni and confectionery products: monograph; ed. by d-a tech. Sciences, Oryol: FGOU VPO "State University-UNPK", 2011: 265.

5. Gorbachev, E.G. and Lebedenko, T.E. Potential of medicinal, spicy-aromatic plants in improving the quality of wheat bread. Technology and equipment of foodstuffs. East-European journal of advanced manufacturing sciences, 2014; 12 (68):101-107.

6. Polandova, R.D. and Shneyder, T.I. Priorities of the development of bakery and macaroni products. Baking in Russia. 2000; 4: 3-4.
7. Kulakova, SN, Baykov, VG and Bessonov, VV.Peculiarities of vegetable oils and their role in nutrition. Fat-and-oil industry. 2009; 3:16-20.

8. Shevtsov, AA, Alekseeva TV and Madzhidov RM. Stabilizing the enzymatic activity of raw materials of the plant. Automation and modern technologies, 2009: 1: 64-67.

9. Makhmudov RA, Makienko, YI, and Madzhidov KH. Study of physicochemical parameters of oil from germ flakes of wheat. Storage and processing of farm products. 2006;2:17-19.

10. Grandel, F. Debittering of cereal seed germs. Chem. Abstr, 2009;53: 514.

11. Vedernikova EI, Sabitova TV. The usage of flowing stream in the storage of grain products. Storage and processing of farm products, 2010;1: 12-17.

12. Veldsink, Jan W. Selective hydrogenation of sunflower seed oil in a three-phase catalytic membrane reactor. J. Amer. oil Chem. Soc., 2001;78(5):443-446.

13. Abramov, I. A., Eliseeva, N. E. Kolpakova, V. V. and Piskun, T. I. Amarant: Amaranth: chemical composition, biochemical properties and processing methods. Storage and processing of farm products. 2011: 6: 44-48.

14. Ipatova, L.G. Fatty foods for a healthy diet. Modern view. 2009:396.

15. Ponomareva, O. I. More attention to the use of secondary products of grain processing enterprises.Bakery of Russia. 2000; $6: 19$.

16. Iunikhina, V.S. The use of wheat germ flour in baby food.Food industry. 1997; 6:12.

17. Rodionova, N.S. Development of a plant complex food system based on products of processing wheat germ of balanced fatty acid composition. Fundamental research. 2013; 11:1594-1597.

18. Industrial oilseed raw materials [Electronic resource] . Access mode: http: //www.znaytovar.ru/s/Promyshlennoe-maslichnoesyre.html.

19. The chemical composition of sesame [Electronic resource]. Access mode: http://exex.com.ua/ximicheskij-sostav-kunzhuta. htm.

20. GOST 30623-98. Vegetable oils and margarine products. Falsification detection method .Access mode: http://docs.cntd.ru/ document / gost-30623-98.

21. Klimantova E. V. and Nekrasova T. E. The vitamins of fat-andoil products. Oil and fat industry. 2000; 1: 32-34.

22. We reveal the secrets of how rapeseed oil is useful [Electronic resource]. - Access mode: https: //www.inmoment.ru/beauty/ health-body/rape-oil.html.

23. Rakhmonov KS. Influence of leavens of spontaneous fermentation and Phyto-additives on the provision of microbiological safety. Journal of Critical Reviews. 2020;7(5): 850-860.

24. Jabborova SK.Application of products of processing mulberries and roots of sugar beet in the production of cupcakes. Journal of Critical Reviews .2020;5(5): 277-286.

25. K.S.Rakhmonov. Application of Phyto-supplements from medicinal vegetable raw materials in the production of drugs. Journal of Critical Reviews.2020; 7, (12): 934-941.

26. N.R.Barakayev. Improvement of the design of mobile equipment for post-harvest processing of crops.Journal of Critical Reviews.2020;7, (14): 306-309. 